\title{
ORIENTATIONAL EFFECTS AND INFLUENCE OF DELTA PHASE ON FATIGUE CRACK GROWTH RATES IN A FORGED DISC OF INCO718 SUPERALLOY
}

\author{
S. Ponnelle ${ }^{1}$; B. Brèthes ${ }^{2}$; A. Pineau ${ }^{3}$ \\ ' SNECMA Moteurs, Etablissement de Gennevilliers, Gennevilliers 92 (France) \\ 2 SNECMA Moteurs, Etablissement de Villaroche, Moissy-Cramayel 77 (France) \\ ${ }^{3}$ Ecole des Mines de Paris, Centre des Matériaux, BP87, EVRY Cedex 91003 (France)
}

\begin{abstract}
The fabrication route of 718 turbine discs involves several thermomechanical operations of forging and circular rolling, which result in a strong microstructural orientation of the material and especially of the distribution of $\delta$ phase and carbide particles (here called Forming Induced Arrangement - FIA). Fatigue Crack Growth Rates (FCGR) were measured on specimens cut from an industrial turbine disc along various crack orientations. These tests were performed at $650{ }^{\circ} \mathrm{C}$ under fatigue and creep-fatigue conditions $\left(t_{h}=5 \mathrm{~min}\right)$. Two types of specimens were used, conventional CT specimens ( $W=40 \mathrm{~mm}$ ) and smaller $\mathrm{KB}$ specimens containing a small $3 \mathrm{D}$ semi-elliptical EDM notch $(0.3 \mathrm{~mm})$.

Under air conditions, large differences were observed between the various orientations of crack front according to FIA. It is shown that the FCGR are the higher when the crack front is parallel to the microstructural layers formed by the alignment of $\delta$ and carbide particles, whereas slower rates are measured when the crack front is perpendicular to them. Moreover, no significant hold time effects were observed along this latter direction. S.E.M. observations showed that the fracture mode is predominantly intergranular when FCGR are the higher and essentially transgranular when the crack propagates along the other directions. Arrangement of $\delta$ phase seems to play the major role on these differences. 3D effects observed on small $\mathrm{KB}$ specimens are discussed according to arrangement of the aspect ratio of the semi-elliptical cracks. Under vacuum conditions, no difference exists between each extraction position and all cracks remain semi-circular while the fracture mode is both transgranular and intergranular.

Final conclusions about suitable arrangement of $\delta$ phase in components are drawn.
\end{abstract}

Superalloys 718.625 .706 and Various Derivatives

Edited by E.A. Loria

TMS (The Minerals. Metals \& Materials Society). 2001 


\section{Introduction}

Fatigue crack propagation in INCO718 has been studied for years by materials scientists as well as engineers, with a view to guarantee a high reliability for critical aeronautical engine components. However, relatively few studies have been made on specimens extracted from real parts, INCO718 bars often being chosen to machine specimens. In the present work, all the specimens were cut from a standard turbine disc. The alloy fatigue crack propagation behaviour was studied at $650^{\circ} \mathrm{C}$, a very high temperature for INCO718, in order to explore the alloy limitations.

At such a temperature, it is essential to study dwell-time effects as it was shown that cycles including a hold time at maximum load lead to increased crack propagation rates when compared to triangular cycles tests results [1,2]. Broadly speaking, cycle frequency is a key parameter for INCO 718 crack propagation at high temperature. Intergranular cracking is linked with time-dependent crack propagation and low cycle frequencies [3]. On the other hand, under high frequency loading cycles, transgranular crack propagation is related to a cycle-dependent behaviour. Microstructural features, such as grain size and morphology, play a major part in the alloy crack propagation resistance at high temperature [2].

In this work, these parameters were studied using fatigue crack propagation tests performed under $10 \mathrm{~s}-10 \mathrm{~s}$ triangular loading cycles (continuous fatigue), as well as $10 \mathrm{~s}-300 \mathrm{~s}-10 \mathrm{~s}$ trapezoidal cycles $(300 \mathrm{~s}$ hold time at maximum load : hereafter called creep-fatigue conditions). Specimens were extracted from the disc with various orientations, so that crack propagation rates could be analysed in relation to microstructural features due to the industrial fabrication route.

\section{Materials and experimental procedures}

\section{Material}

The material INCO 718 (NC19FeNb) used for critical components belongs to the Premium Quality class. Its precise chemical composition is severely controlled thanks to a vacuum induction melting process, followed by a vacuum arc remelting second step. The mean alloying elements weight percentages are : $\mathrm{Cr}=17.9 \%, \mathrm{Fe}=18 \%, \mathrm{Nb}=5.27 \%, \mathrm{Mo}=2.97 \%, \mathrm{Co}=0.46 \%$, $\mathrm{Ti}=1.01 \%, \quad \mathrm{Al}=0.46 \%, \quad \mathrm{C}=0.027 \%, \mathrm{Ta}=0.01 \%, \quad \mathrm{Mn}, \mathrm{Si}=0.07 \%, \quad \mathrm{~S}=0.0005 \%, \quad \mathrm{P}=0.008 \%$, $\mathrm{B}=(0.0028 \%, \mathrm{Mg}=24 \mathrm{ppm}, \mathrm{Ca}<50 \mathrm{ppm}, \mathrm{Ag}, \mathrm{Pb}<5 \mathrm{ppm}, \mathrm{Bi}<0.3 \mathrm{ppm}$. Sn $<20 \mathrm{ppm}$.

After forging and rolling operations, a standard heat treatment was applied to the disc :

Quenching: $\quad 955^{\circ} \mathrm{C} / 1$ hour $/$ air cooling

Aging treatments : $\quad 720^{\circ} \mathrm{C} / 8$ hours $/$ controlled cooling rate at $50^{\circ} \mathrm{C}$ per hour

$620^{\circ} \mathrm{C} / 8$ hours / air cooling

The nucleation of $\gamma^{\prime}\left(\mathrm{Ni}_{3}(\mathrm{Al}, \mathrm{Ti})\right)$ and $\gamma^{\prime \prime}\left(\mathrm{Ni}_{3} \mathrm{Nb}\right)$ hardening precipitates occurs during the first aging treatment at $720^{\circ} \mathrm{C}$, while the size of these particles grow during the second aging treatment at $620^{\circ} \mathrm{C}$. The disc grain size is $9-10$ ASTM.

$\gamma$ " precipitates are metastable and the stable state is an orthorhombic phase called $\delta$ phase. The $\gamma$ ' precipitates volume fraction is about $15 \%$. The $\delta$ phase precipitates appear as $100 \mathrm{~nm}$ needles or as globular plates which are about $200 \mathrm{~nm}$ thick and 1 or $2 \mu \mathrm{m}$ large in diameter.

In a forged and rolled disc, as the material chosen for this study, carbides and $\delta$ phase particles are not randomly distributed. Their alignment can be linked to the existence of a few hundred microns thick bands, referred to as FIA (Forming Induced Arrangement). The $\delta$ phase content differs slightly from one band to the other, several $\delta$ phase alignments belonging to one band. On figure 1, it can be seen that the arrangement of cellular $\delta$ phase closely corresponds to FIA. In each alignment, $\delta$ phase plates have, on the whole, similar orientations. For instance, in the area shown on figure 1 , the basal plane of cylindrical $\delta$ phase particles is perpendicular to the $z$ - 
axis. On each zone of the disc, such a preferential orientation is inherited from the last two steps of the disc manufacturing route, which includes circular rolling and matricial forging performed at lower temperatures than $\delta$ solvus, contrary to the first manufacturing sequences. Thus, two types of $\delta$ phase precipitates co-exist in the disc. $\delta$ phase needles precipitate during the heat treatment after forging and rolling sequences, whereas globular precipitates nucleate during the forming route.

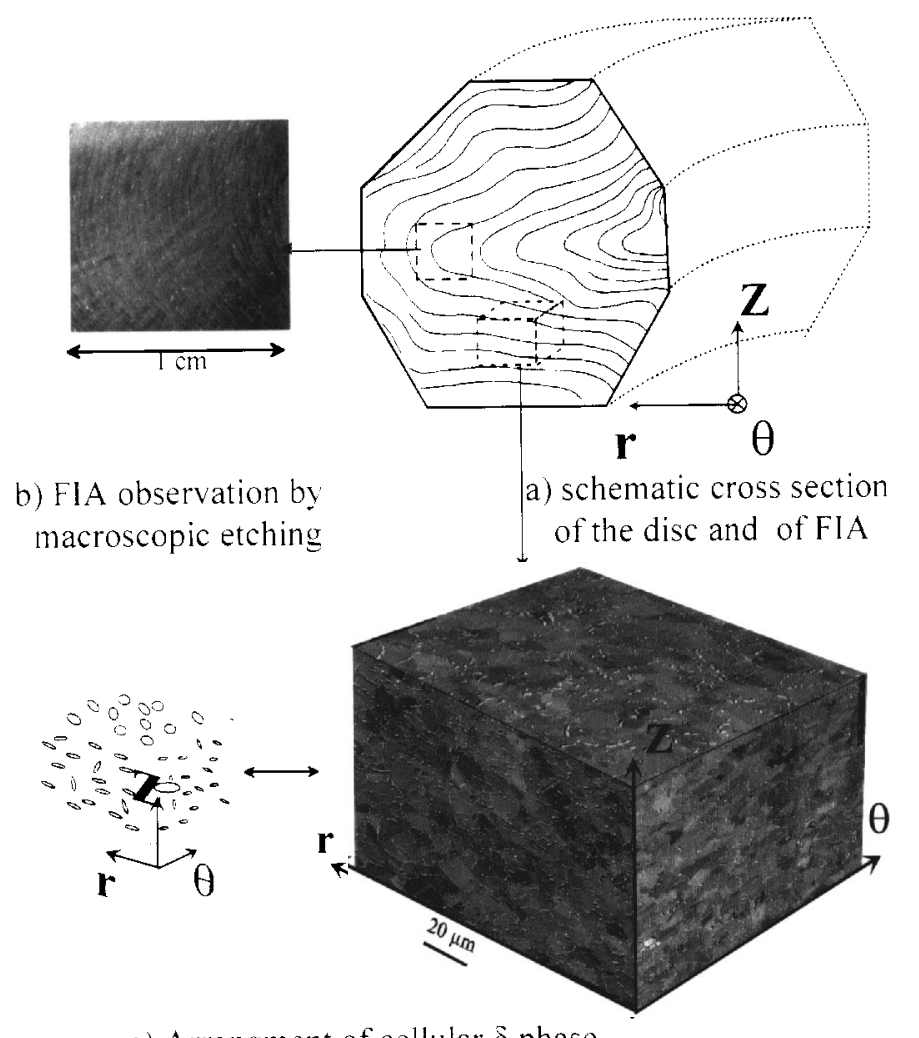

c) Arrangment of cellular $\delta$ phase

Figure 1: Turbine disc microstructure.

\section{Specimens}

In this study, two types of crack propagation specimens were tested. Standard compact tension (CT) specimens were used for 2D long cracks. Plate-like KB specimens were used to study 3D shorter cracks. The geometry of KB specimens is given on figure 2.
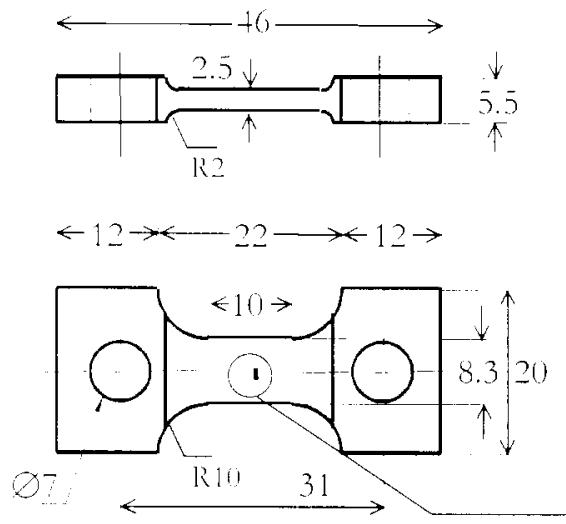
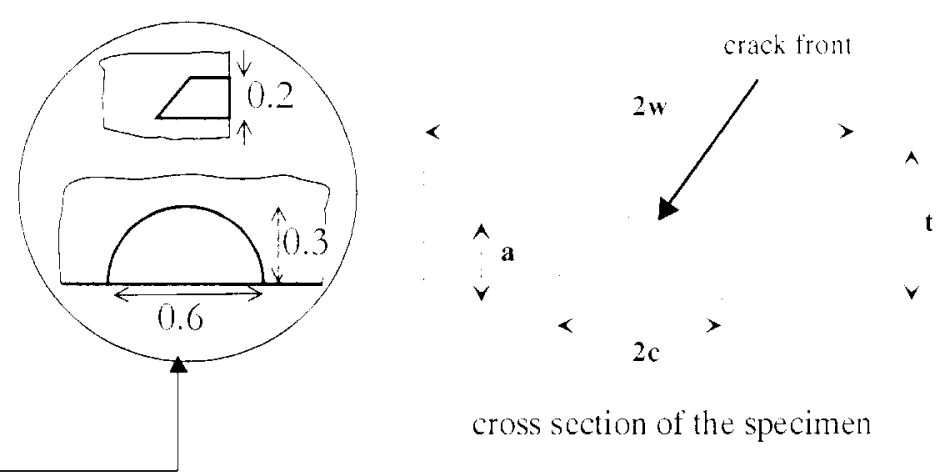

cross section of the specimen

Figure 2 : 3D-cracks specimens geometry. 
Machined by spark-erosion, a semi-circular geometrical defect was made in the centre of the gage length of each KB specimen with in-plane dimensions of $8.3 \times 2.5 \mathrm{~mm}^{2}$. Defect geometry and measurements are given on figure $2: 2 c_{0}=0.6 \mathrm{~mm}$ (long axis of the ellipse) $\mathrm{a}_{0}=0.3 \mathrm{~mm}$ (half of the small axis of the ellipse); $T=0.2 \mathrm{~mm}$ (thickness).

Various orientations were chosen to extract 2D-crack (CT) and 3D-crack (KB) specimens (figure 3).
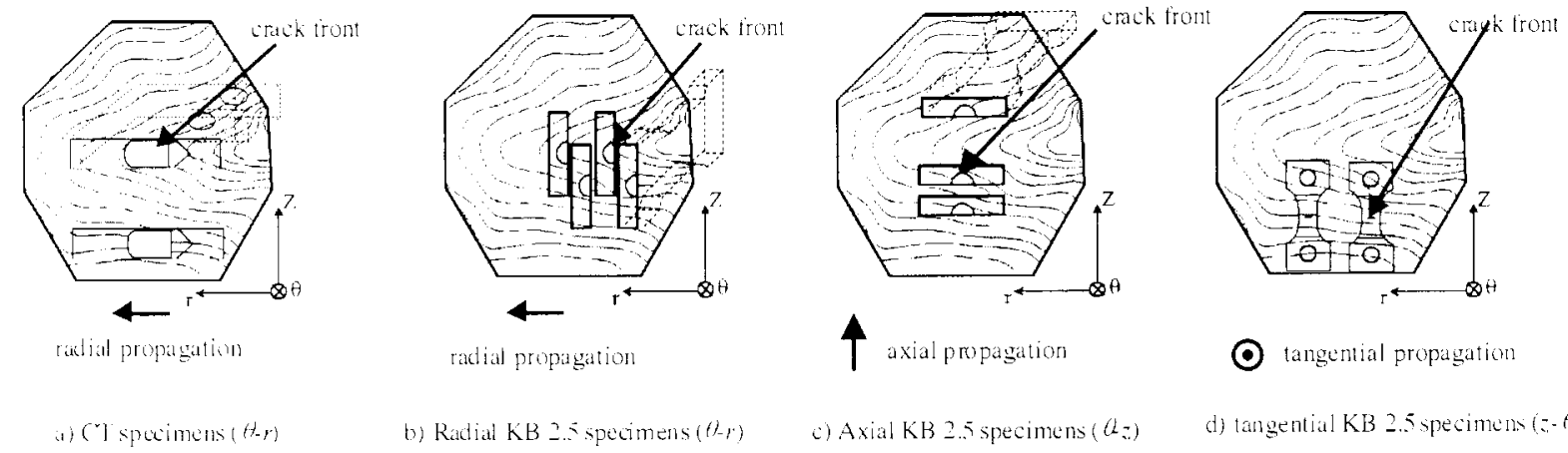

tangential propagation

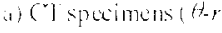

b) Radial KB 2... specimens $(t-r)$

c) Axial KB 2.5 specimens ( $(2-3)$

d) tangential KB 2.5 specimers $(--0)$

Figure 3 : Specimens locations in the disc.

The aim of the study was to compare crack propagation rates for various crack front orientations with regard to FIA. In some specimens, such as those taken from the middle of the disc on figure $3 \mathrm{a}$, the crack is parallel to FIA. On the contrary, for the bottom specimen of figure $3 \mathrm{a}$, the crack front is perpendicular to FIA. At last, on some specimens, the crack can propagate between FIA (tangential KB specimens, figure $3 \mathrm{~d}$ ).

\section{Crack propagation tests}

Crack propagation tests were performed on MTS servo-hydraulic machines, or on an electromechanical machine. Specimens were pre-cracked at ambient temperature and high frequency (20) to $40 \mathrm{~Hz}$ ), with a load ratio $\mathrm{R}=\mathrm{Pmin} / \mathrm{Pmax}=0.1$. The first pre-cracking sequence is followed by a second pre-cracking sequence, consisting in applying $10 \mathrm{~s}-10 \mathrm{~s}$ triangular cycles at $650^{\circ} \mathrm{C}$. In order to create a larger plastic zone at the crack tip than the one obtained at ambient temperature, the applied stress is higher during the last pre-cracking sequence than during the first step. Electrical potential drop technique was used to measure crack propagation rates. Alumel wires were welded on CT specimens notch tips. Very fine wires $(0.1 \mathrm{~mm}$ diameter) were used for KB specimens, on account of the small size of the initial defect. For these specimens, wires were welded $0.5 \mathrm{~mm}$ from the defect. Moreover, three thermocouples were welded on each specimen to control the temperature.

Tests were performed at $650^{\circ} \mathrm{C}$, with constant minimum and maximum loads $(\mathrm{R}=\mathrm{Pmin} / \mathrm{Pmax}$ $=0.1) .10 \mathrm{~s}-10 \mathrm{~s}$ triangular cycles were applied, as well as $10 \mathrm{~s}-300 \mathrm{~s}-10 \mathrm{~s}$ trapezoidal cycles, the later including a $300 \mathrm{~s}$ dwell-time. The electrical signal was recorded every cycle. For $10 \mathrm{~s}-10 \mathrm{~s}$ cycles, the average value was calculated for the whole $20 \mathrm{~s}$ cycle duration. For $10 \mathrm{~s}-300 \mathrm{~s}-10 \mathrm{~s}$ cycles, the average was calculated for the last ten seconds before the unloading ramp. For each type of specimen, a calibration curve was determined to measure the crack length as a function of the electrical potential value [4]. 


\section{Crack propagation results}

2D-crack propagation rates

Plasticity being confined near the crack tip, crack propagation rates can be analysed using a standard stress intensity factor polynomial formula for CT specimens [5].

CT specimens, extracted as shown on figure $3 \mathrm{a}$, were tested at $650^{\circ} \mathrm{C}$, under $10 \mathrm{~s}-10 \mathrm{~s}$ and $10 \mathrm{~s}-$ $300 \mathrm{~s}-10 \mathrm{~s}$ cycles. da/dN vs $\Delta \mathrm{K}(=\mathrm{Kmax}-\mathrm{Kmin})$ curves are shown on figure 4.

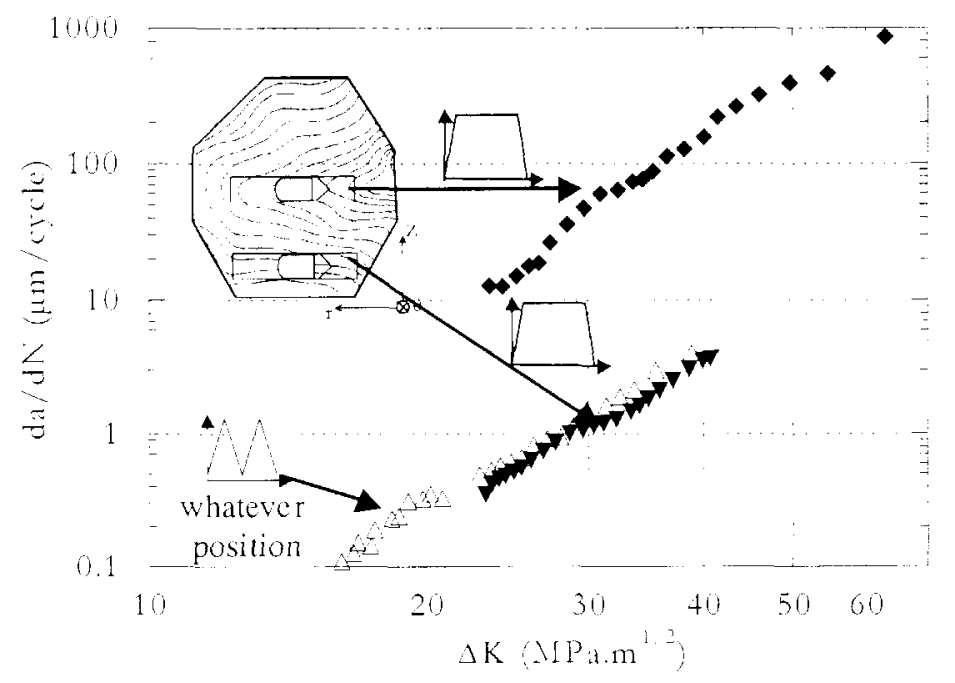

Figure 4 : 2D-cracks propagation rates

For a crack front parallel to FIA, dwell-time effect leads to increased crack propagation rates compared to continuous $10 \mathrm{~s}-10 \mathrm{~s}$ cycling. For a stress intensity factor range of $30 \mathrm{MPa} \cdot \mathrm{m}^{1 / 2}$, crack propagation rates are 50 times higher with $10 \mathrm{~s}-300 \mathrm{~s}-10 \mathrm{~s}$ cycles than with $10 \mathrm{~s}-10 \mathrm{~s}$ cycles, which is in good agreement with what is usually reported in literature. On the other hand, in figure 4 , it is observed that when the crack front is perpendicular to FIA, there is no dwelleffect at all, crack propagation rates being similar for both types of cycles.

\section{D-crack propagation rates}

3D-crack specimens of various orientations were also tested under the same loading cycles. Stress intensity factors were calculated using Newman and Raju equations [6] for semielliptical cracks, which were modified to take into account crack aspect ratios greater than 1 $[7,8]$.

Figure 5 summarises all the test results obtained for the three crack propagation orientations: radial (figure 3b), axial (figure $3 \mathrm{c}$ ) and tangential (figure $3 \mathrm{~d}$ ). When not mentioned, the wave form signal is trapezoidal, including a 300 s dwell-time. Several tests were performed for each orientation and bands are used on the graph to show the scatter in test results. Crack shapes are also given on figure 5 for each orientation, $\alpha=\mathrm{a} / \mathrm{c}$ being the crack aspect ratio.

For 10 s-10s cycles, radial and axial cracks lead to similar crack propagation rates, tangential cracks propagation rates being four times higher. As expected, under 10s-300s-10s cycles, langential cracks propagate very quickly, as much as 50 times faster than under 10s-10s cycles. On the other hand, there is no detrimental effect of dwell-time for axial cracks, the propagation rates being the same for triangular and trapezoidal cycles. Last but not least, radial crack 
propagation rates are very scattered, by about two orders of magnitude. For this last crack orientation, some crack fronts are parallel to FIA whereas others are perpendicular.

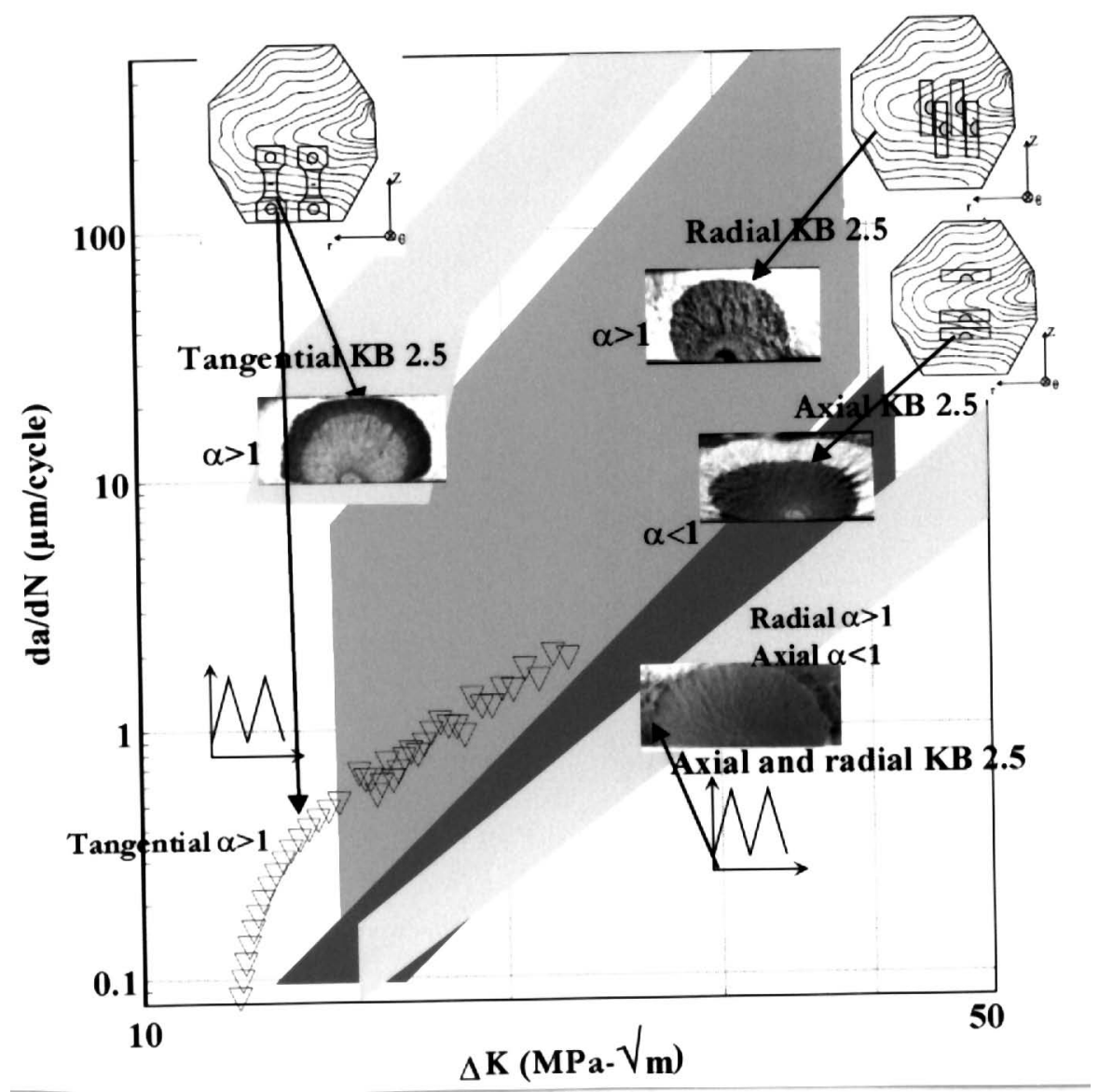

Figure 5 : 3D-cracks propagation rates

\section{Fractography}

Scanning Electron Microscopy (SEM) examinations of a tangential KB specimen crack (figure 6) show that numerous $\delta$ phase fine plates are present on the crack path. Moreover, this crack path seems to be guided by the interfaces between $\delta$ phase particles and the matrix. In this example, crack propagated between $\delta$ phase alignments.

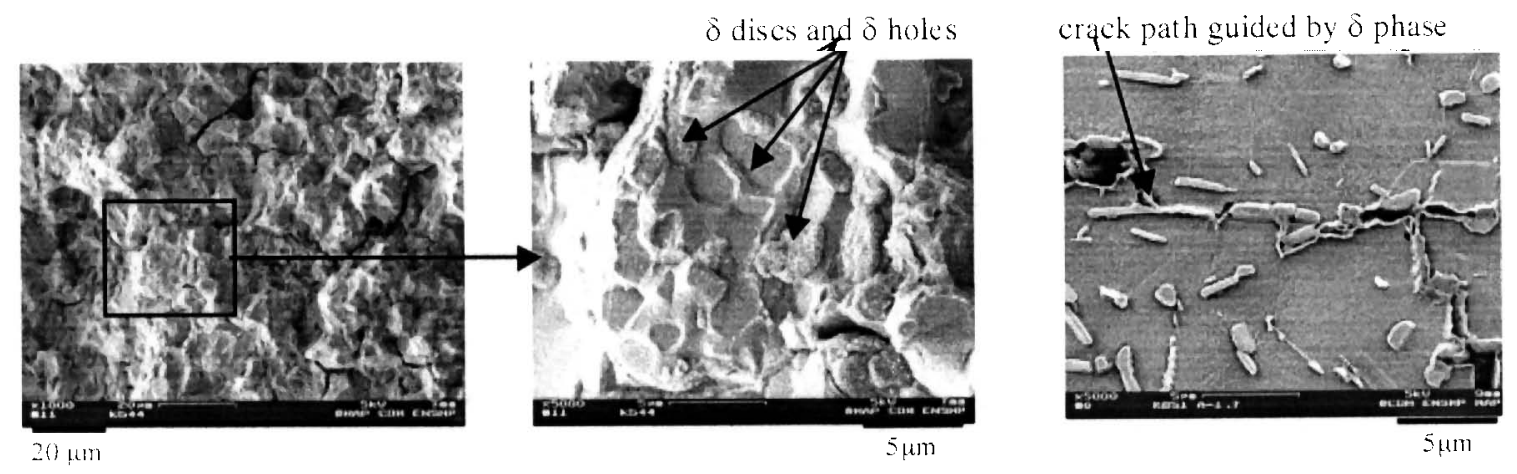

Figure 6 : Fatigue crack path along $\delta$ phase particles 


\section{Discussion}

\section{Environmental effects}

Previous studies showed that dwell-time effect at high temperatures on nickel base superalloys is largely related to environmental effects $[9,10]$. On INCO718 and N18 alloy, no detrimental effect of dwell-time was observed for oxygen partial pressures lower than $10^{-3} \mathrm{mbar}$.

Further crack propagation tests under $10 \mathrm{~s}-300$ s-10s cycles were performed on $\mathrm{KB}$ specimens in vacuum $\left(2.10^{-6}\right.$ mbar). Results are reported on figure 7 . In this figure, it is observed that whatever the crack orientation, the crack propagation rates are identical and the crack shape remains semi-circular. Moreover, fatigue crack growth rates are slightly lower than those obtained in air with triangular cycles.

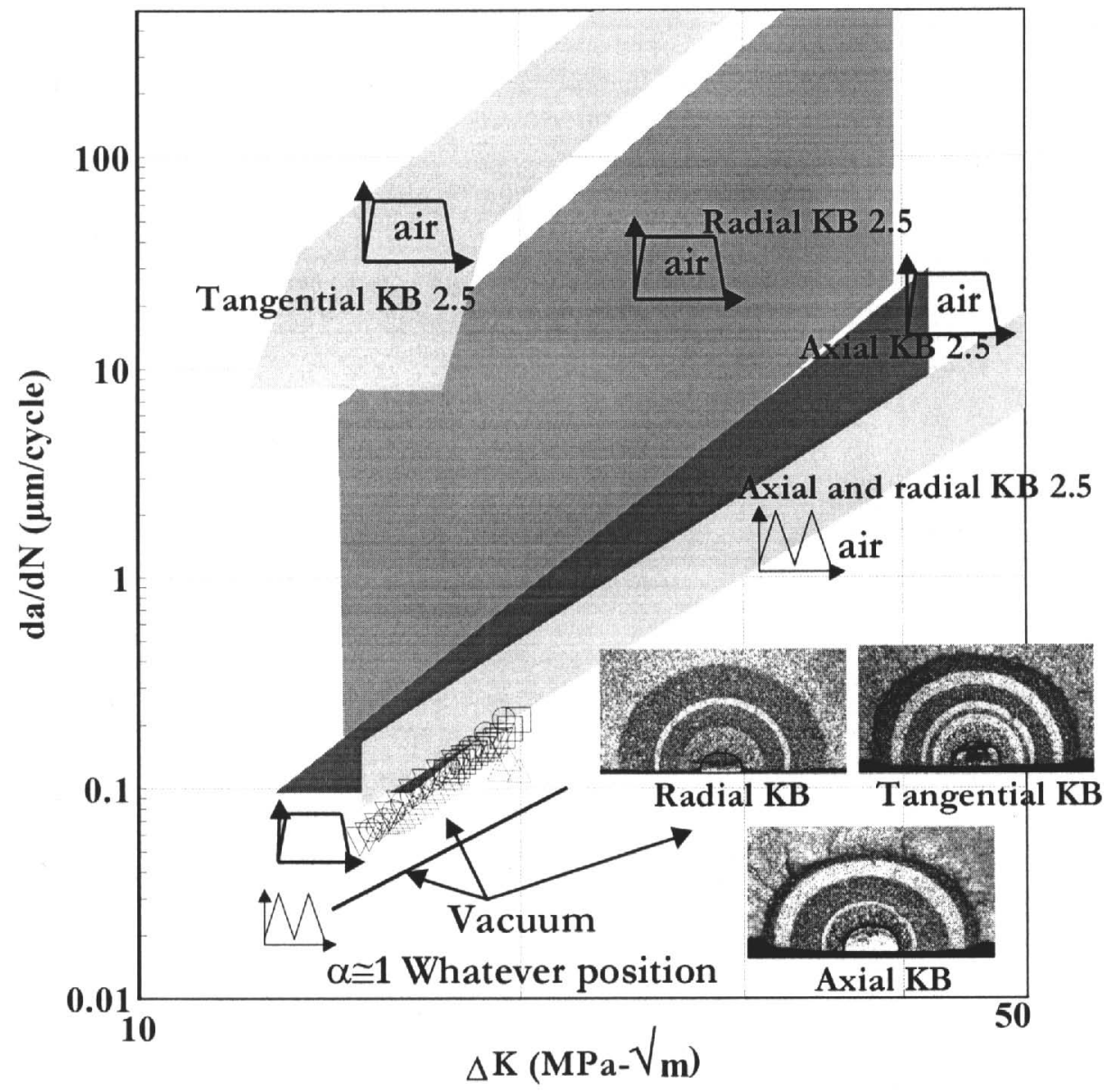

Figure 7 : Environmental effects, crack propagation rates and crack shapes in vacuum

Therefore, in vacuum, there is no influence of crack orientation on INCO 718 crack propagation properties. Pédron and Pineau also found that INCO718 with different grain sizes leads to identical crack propagation rates in vacuum whereas they lead to very different rates in air [2].

\section{Crack front interactions with FIA}

A simple model of periodically distributed bands, made of crack resistant material or poor crack resistant material can be drawn (Figure 8). When a CT crack front is perpendicular to FIA, the 2D crack propagation is slowed down by crack growth resistant material. On the contrary, when a crack is parallel to FIA, it propagates faster as a parallel vs. serial electrical 
circuit analogy would predict (Figure $8 \mathrm{a}$ and $8 \mathrm{~b}$ ). This scheme can also give information on the possible effect of FIA on the crack aspect ratios of 3D defects (Fig $8 \mathrm{c}, \mathrm{d}$ ), even if the global growth rate of the defect seems to be difficult to predict. Nonetheless, when the crack propagates between two bands of resistant material, the propagation rate is expected to be very high (figure 8e). Indeed, this configuration corresponds to tangential cracks which gave rise to the highest crack propagation rates (figure 5).

In radial crack KB specimens, crack front and FIA interactions can vary a lot from one specimen to the other, FIA shape being quite complex in the middle of the disc. Thus, this variability may explain the largely scattered crack propagation rates for these specimens. For axial specimens, large parts of the crack front can be slowed down by perpendicular FIA, leading to low propagation rates and crack aspect ratios $\mathrm{a} / \mathrm{c}<1$. Such crack aspect ratios are in contradiction with the tunneling effect often mentioned in literature, for $\mathrm{Ni}$ base superalloy submitted to dwell-time cycles in air $[11,12]$. On the contrary, KB specimens with a tangential crack exhibit such a tunneling effect $(\mathrm{a} / \mathrm{c}>1)$, since in that case the crack propagation is not slowed down by FIA.

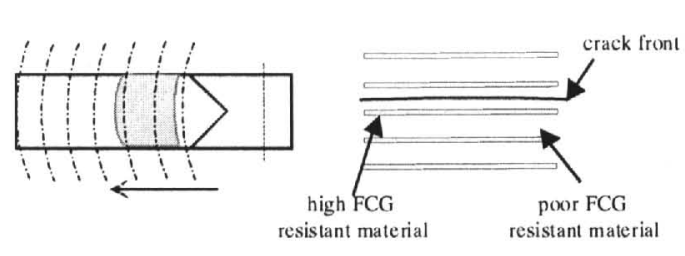

(a)

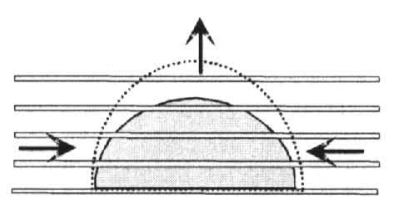

(c)

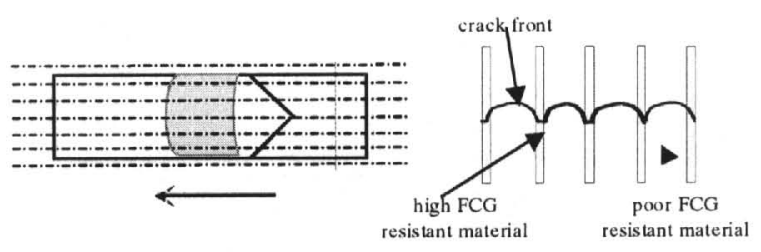

(b)

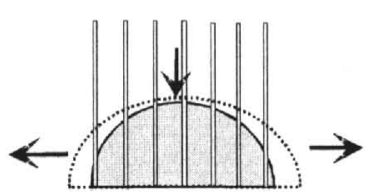

(d)

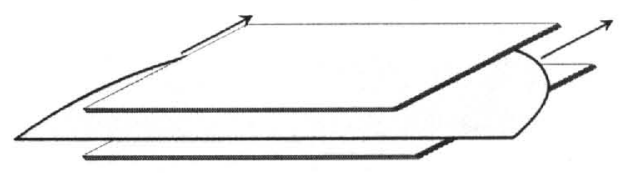

(e)

Figure 8 : FIA and crack front interactions.

In order to better understand crack and FIA interactions, crack front microstructural examinations were performed after testing. Secondary cracks were observed perpendicularly to crack fronts which are perpendicular to FIA (figure 9). On figure 9b, the distance between ridges observed on the crack surface is consistent with the distance between FIA. These asperities may induce a significant crack closure effect and decrease the crack growth rates. Moreover, delamination (figure 9c), leading of a multiple layer material, may induce a great reduction on the crack driving force. Indeed, each layer is under plane stress condition instead of the plane strain state of the bulk material. 
(a)

(b)
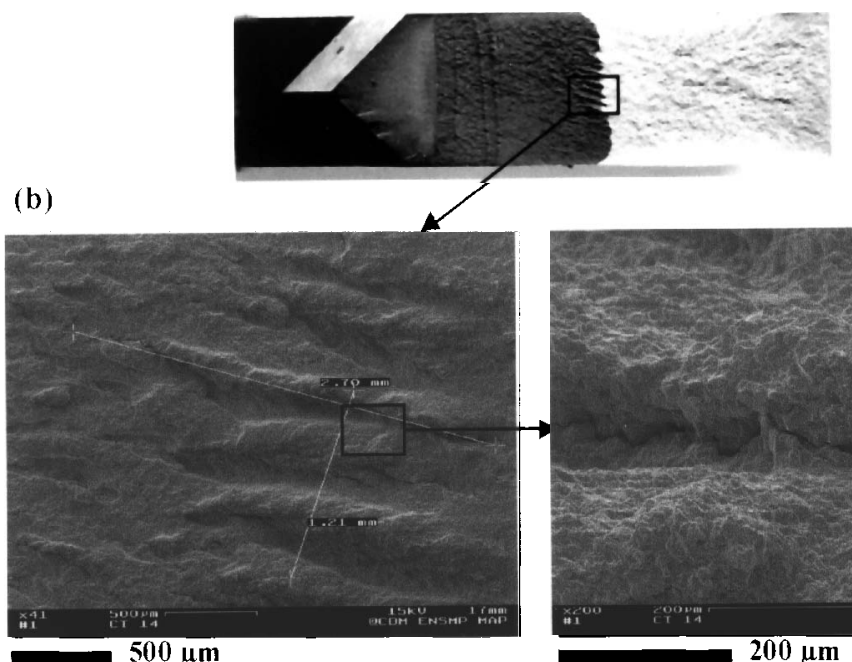

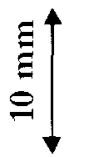

(c)

Figure 9 : Perpendicular secondary cracks on a 2D-crack front, a delamination mechanism

This delamination mechanism can be related to $\delta$ phase alignments as suggested by figure 6 . The influence of $\delta$ phase on crack propagation under a dwell-time cycle was reported in a previous work by Lynch et al [13]. These authors showed the lack of a dwell-time effect on crack propagation rates at $700^{\circ} \mathrm{C}$ in INCO718DA. The experiments involved $2 \mathrm{~Hz}$ triangular cycles, and $0.25 \mathrm{~s}-60 \mathrm{~s}-0.25 \mathrm{~s}$ trapezoidal cycles. Both types of cycles led to the same crack propagation rates. Specimens were extracted from a very fine grain disc, containing many $\delta$ phase particles. From these results, it may be concluded that $\delta$ phase particles are beneficial for fatigue crack propagation properties with a dwell-time cycle. However, the chosen $2 \mathrm{~Hz}$ cycle involved transgranular crack propagation. As a result, loading conditions must be cssentially cycle-dependent. Therefore, the dwell-time effect must not be as marked as for a time-dependent loading ramp. It would have been very interesting to perform tests on this INCO718 DA with trapezoidal cycles including longer ramps. In our study, 10s-10s cycles led to intergranular cracking, suggesting a partially time-dependent behaviour.

In this time-dependent regime, $\delta$ phase alignments can entail crack branching as shown on figure 10. On this CT specimen, crack branching can be related to $\delta$ phase alignments orientations. This last experiment confirms the essential part played by $\delta$ phase alignments on crack propagation under trapezoidal cycles at high temperature.

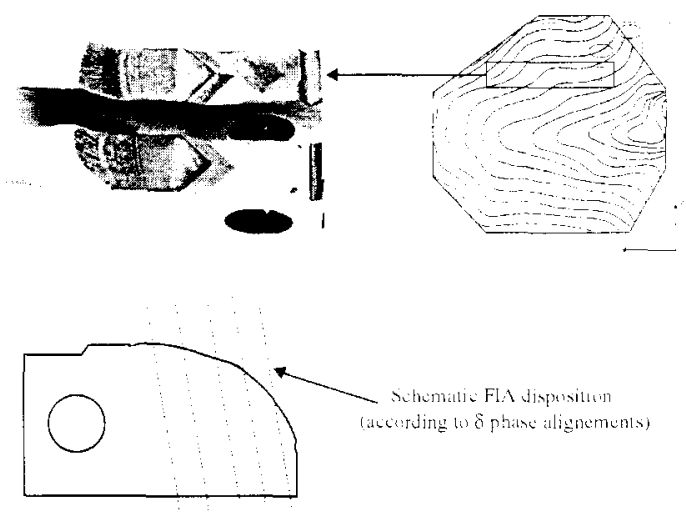

Figure 10: FIA and crack bifurcation in a CT specimen 


\section{Conclusions and prospects}

In spite of all the studies performed on INCO718, the present work has shown that a number of improvements can be brought on the FCGR behaviour and knowledge of this alloy.

In this work, very large variations in crack propagation rates were obtained with trapezoidal 10 s-300s-10s loading cycles. Some results showed no detrimental effect of dwell-time on crack propagation rates at $650^{\circ} \mathrm{C}$.

These variations were found to be related to crack front orientations with regard to forming induced arrangement. Such arrangement is consistent with $\delta$ phase alignment due to the disc manufacturing route. Crack front interactions with $\delta$ phase particles explain the various crack front shapes and crack propagation rates obtained in this study.

The highest crack growth rates correspond to a crack propagating between $\delta$ phase alignements. On the contrary, a delamination mechanism entailing crack closure and a reduction of stress triaxiality can explain low propagation rates for crack fronts perpendicular to $\delta$ phase alignments.

Rolling and forging conditions, as well as heat treatment sequences, should be optimised to get $\delta$ phase alignments perpendicular to the most hazardous cracks in real discs. For instance, it would be convenient to develop FIA perpendicular to potential radial cracks in the most

severely loaded areas. Such preferential local microstructures may enable designers to use INCO718 at temperatures as high as $650^{\circ} \mathrm{C}$.

\section{References}

1. K. Sadananda and P. Shahinian, "Crack growth under creep and fatigue conditions," TMS-AIME, ed. R.M. Pelloux and N.S. Stollof, 1980, 86-111.

2. J.P. Pédron and A. Pineau, "The effect of microstructure and environment on the crack growth behaviour of Inconel 718 alloy at $650^{\circ} \mathrm{C}$ under fatigue, creep and combined loading," Materials Science and Engineering, 56 (1982), 143-156.

3. H. Ghonem, T. Nicholas and A. Pineau, "Elevated temperature fatigue crack growth in alloy 718 ," Fatigue and Fracture of Engineering Materials and Structures, 16 (1993), 565-590.

4. S. Ponnelle, "Propagation de fissures par fatigue à haute température dans l'alliage 718 : Effets de microstructure et de chargements complexes" (Ph.D. thesis, Ecole Nationale Supérieure des Mines de Paris, 2001).

5. J. R. Haigh and C.E. Richards, "Yield point loads and compliance functions of fracture mechanics specimens" (laboratory memorandum RD/L/M/461, Central Electric Research Laboratories, 1974).

6. J. C. Newman and I. S. Raju, "An empirical stress intensity factor equation for the surface crack," Engineering Fracture Mechanics, 12 (1981), 185-192.

7. X. Wang and S.B. Lambert, "Stress intensity factors for low aspect ratio semi-elliptical surface cracks in finite thickness plates subjected to nonuniform stresses," Engineering Fracture Mechanics, 51 (1995), 517-532.

8. X. Wang and S.B. Lambert, "Stress intensity factors and weight functions for high aspect ratio semielliptical surface cracks in finite thickness plates," Engineering Fracture Mechanics, 57 (1997), 1324

9. R. Molins, G. Hochstetter, J.C. Chassaigne and E. Andrieu, "Oxidation effects on the behaviour of alloy 718 at high temperature," Acta Mater., 45 (1997), 667-674.

10. E. Andrieu and A. Pineau, "Study of coupled phenomena involved in the oxidation assisted intergranular cracking of Ni based superalloys" (Paper presented at EUROMECH, Oxford, U-K, November 1998).

11. J. M. Rongvaux, J. C. Lautridou and J. Y. Guédou, "Etude du comportement des fissures courtes sur l'INCONEL 718" (SNECMA internal report, 1987).

12. J. Tong et al., "A comparison of corner notched and compact tension specimens for high temperature fatigue testing" (Paper presented at "Engineering Against Fatigue", Sheffield, U-K, March 1997).

13. S. P. Lynch, T. C. Radtke, B. J. Wicks and R. T. Byrnes, "Fatigue crack growth in Ni-based superalloys at $500-700^{\circ} \mathrm{C}$. Part 11 : Direct aged alloy 718," Fatigue and Fracture of Engineering Materials and Structures, 17 (1994), 313-325. 